\title{
Pengaruh edukasi seksual terhadap perilaku seks pranikah pada generasi milenial
}

\section{The effect of sexual education on pranicah sex behavior in} millennial generation

\author{
Wellina BR Sebayang ${ }^{1, *}$, Griselli Saragih ${ }^{2}$ \\ ${ }^{1,2}$ Universitas Imelda Medan, Jalan Bilal Ujung No.52, Pulo Brayan Darat I, Medan, Sumatera Utara 20239, \\ Indonesia \\ ${ }^{1}$ wellinasebayang@gmail.com ${ }^{*}{ }^{2}$ griselli.srgh@gmail.com \\ *corresponding author
}

Tanggal Submisi: 2 September 2019, Tanggal Penerimaan: 10 Oktober 2019

\begin{abstract}
Abstrak
Tujuan penelitian ini adalah untuk mengetahui pengaruh edukasi seksual terhadap perilaku seks pranikah pada generasi milenial. Metode penelitian menggunakan quasiexperimental one group pretest-posttest design, lokasi di SMK Imelda Medan, total sampel 180 orang. Instrumen yang digunakan dalam penelitian ini adalah wawancara kuisioner. Hasil penelitian menunjukkan bahwa responden berisiko melakukan hubungan seks pranikah mengalami penurunan dari $87(48,3 \%)$ menjadi 42 orang $(23,3 \%)$. Hasil analisis statistik uji $\mathrm{T}$ didapat edukasi seksual mempunyai pengaruh terhadap perilaku seks pranikah pada generasi milenial $(p=0,01 ; p<0,05)$. Saran penelitian selanjutnya dengan desain yang berbeda.
\end{abstract}

Kata kunci : edukasi seksual; seks pranikah; generasi milenial

\begin{abstract}
The purpose of this study was to determine the effect of sexual education on premarital sexual behavior in the millennial generation. The research method uses a quasiexperimental one-group pretest-posttest design, location at SMK Imelda Medan, a total sample of 180 people, research instrument interview questionnaire.

The results of the study, after receiving sexual education, respondents at risk of having premarital sex decreased from $87(48.3 \%)$ to 42 people $(23.3 \%)$. The results of the statistical analysis of the T-test found that sexual education influenced premarital sexual behavior in the millennial generation $(p=0.01 ; p<0.05)$, suggestions for next research with different designs.
\end{abstract}

Keywords: sexual education; premarital sex; the millennial generation

\section{PENDAHULUAN}

Edukasi seksual di Indonesia belum berjalan maksimal, hasil beberapa penelitian menyimpulkan bahwa pengetahuan remaja tentang seksual masih rendah. Generasi milenial khususnya yang lahir di tahun 2000 dan seterusnya, sudah terpapar dunia internet sejak usia dini. Dunia internet dengan segala daya tarik dan situs porno yang sangat mudah diakses dapat berdampak buruk terhadap generasi milenial sebagai 
generasi penerus bangsa. Data remaja yang berusia 10-24 tahun menurut hasil sensus penduduk tahun 2010 adalah $27,6 \%$ dari sekitar 64 juta jumlah penduduk Indonesia. Jumlah yang besar ini harus mendapat perhatian, untuk mempersiapkan manusia yang sehat secara jasmani, rohani, mental dan spiritual, karena remaja merupakan generasi penerus bangsa (BKKBN, 2012).

Permasalahan utama generasi milenial saat ini adalah masalah perilaku seksual. Penelitian PKBI (Perkumpulan Keluarga Berencana Indonesia) tahun 2005 di kota Tasikmalaya, Cirebon, Singkawang, Kupang dan Palembang ditemukan bahwa remaja telah melakukan hubungan seks sebanyak $9,1 \%$, dan $85 \%$ dari remaja tersebut telah melakukan hubungan seks dengan pacar pada usia 13-15 tahun (Donggori, 2012). Hasil lembar fakta yang diterbitkan oleh PKBI, United Nation Population Fund Ascosiation (UNFPA) dan BKKBN ditemukan sekitar 15 juta remaja umur 15-19 tahun melahirkan setiap tahun, dari sekitar 2,3 juta kasus aborsi 20\% dilakukan oleh remaja. Fakta lain ditemukan bahwa dari 52 juta remaja sekitar 15\% telah melakukan hubungan seksual di luar nikah pada usia 10-24 tahun. Dari berbagai penelitian mengenai kaum remaja di Indonesia menyimpulkan bahwa nilai-nilai trend hidup remaja saat ini bertoleransi pada gaya hidup seksual pranikah (Prasetyo, 2012).

Masalah yang berkaitan dengan kesehatan reproduksi remaja menjadi salah satu faktor penghambat upaya peningkatan kualitas remaja. Hasil beberapa laporan menyebutkan banyak remaja sudah terjebak perilaku seksual pranikah dan perilaku reproduksi tidak sehat. Beberapa penelitian menyebutkan mayoritas remaja melakukan hungan seks pertama kali pada umur 15-18 tahun saat di bangku SMA. Perilaku seksual pranikah dipengaruhi berbagai faktor baik dari dalam maupun dari luar diri remaja dan ini menjadi persoalan multi dimensional (Soetjiningsih, 2008). Penelitian sebelumnya menyimpulkan bahwa ada tiga faktor yang mempengaruhi perilaku seks pranikah, yaitu kekuatan karakter, konsep diri dan sikap, faktor sikap adalah yang paling besar (Irmawati, L 2013). Penelitian Kusumastuti, W (2017) menyatakan bahwa psikoedukasi tidak mampu mengubah perilaku seks pranikah pada remaja.

Edukasi seksual menjadi sebuah solusi dalam permasalahan generasi millennial. Edukasi seksual yang benar dan tepat akan menjadi payung terhadap maraknya seks bebas dan seks pranikah yang mengancam masa depan remaja. Edukasi seksual harus diberikan sejak dini. Edukasi seksual merupakan tugas bersama, karena itu semua pihak harus terlibat, orang tua atau petugas kesehatan saja tidak cukup.

Edukasi seksual diharapkan menjadi bagian dalam kurikulum pendidikan, dengan demikian setiap anak yang bersekolah dapat memperolehnya secara otomatis. Kenyataan yang ditemukan saat ini bahwa edukasi seksual belum ada di semua sekolah, karena itu melalui penelitian ini diharapkan edukasi seksual dapat memberi pengaruh positif terhadap perilaku seks pranikah pada generasi millennial.

\section{METODE PENELITIAN}

Jenis penelitian menggunakan rancangan quasi-experimental one group pretestposttest design. Populasi adalah seluruh siswa kelas X dan XI laki-laki dan perempuan berjumlah 180 orang. Sampel yang digunakan adalah total sampel 180 responden. Lokasi dilaksanakan di SMK Imelda Medan, J1. Bilal no 52 Pulo, Brayan Darat Medan. Variabel bebas dalam penelitian ini adalah edukasi seksual. Variabel terikat adalah perilaku seks pranikah pada generasi millennial. Pengumpulan data melalui pengisian kuesioner dan wawancara langsung dengan responden. Setelah itu dilakukan analisis 
menggunakan program SPSS, dilanjut dengan uji normalitas. Uji hipotesis yang digunakan adalah uji $T$ berpasangan (paired t-test).

\section{HASIL DAN PEMBAHASAN}

Pada penelitian ini karakteristik responden yang dilihat meliputi jenis kelamin, tempat tinggal dan pekerjaan orang tua. Dapat dilihat pada tabel berikut.

Tabel 1. Distribusi frekuensi karakteristik responden

\begin{tabular}{lcc}
\hline \multicolumn{1}{c}{ Karakteristik Responden } & Jumlah & Persentase \\
\hline Jenis kelamin & & \\
\hline Perempuan & 46 & 25,6 \\
Laki-laki & 134 & 75,4 \\
Jumlah & 180 & 100,0 \\
\hline Tempat tinggal & & \\
Kost & 28 & 15,6 \\
Bersama orang tua & 152 & 85,4 \\
Jumlah & 180 & 100,0 \\
\hline Pekerjaan orang tua & & \\
Buruh & 11 & 6,1 \\
Bertani & 3 & 1,7 \\
Wiraswasta & 93 & 51,7 \\
Karyawan swasta & 58 & 32,2 \\
Guru/ Dosen & 15 & 8,3 \\
Jumlah & 180 & 100,0 \\
\hline Sumber: Data Primer tahun 2019 & &
\end{tabular}

Sumber: Data Primer tahun 2019

Tabel 1 menunjukkan bahwa jenis kelamin sebagian besar responden adalah laki-laki yaitu sebanyak 143 orang $(75,4 \%)$, hal ini didasari SMK tehnik lebih diminati oleh laki-laki dari perempuan. Jumlah perempuan yang sedikit sehingga dibuat pemisahan kelas, hanya 2 kelas yang heterogen laki-laki dan perempuan, sebagian besar kelas homogen. Penelitian Hastuti (2018) menyatakan bahwa perilaku seksual lebih berisiko pada kelas homogen (laki-laki dan wanita dipisahkan kelas) dari pada kelas heterogen (laki-laki dan wanita dalam satu kelas), hal ini sependapat dengan hasil penelitian bahwa mayoritas responden jenis kelamin laki-laki yaitu 143 orang (75,4\%), artinya semakin terbatas komunikasi antara laki dan perempuan membawa perilaku yang tabu dan canggung terhadap lawan jenis dan meningkatkan perilaku seks yang berisiko.

Responden tinggal bersama orang tua yaitu sebanyak $152(85,4 \%)$ dan ada $15,6 \%$ yang kos dekat sekolah karena tempat tinggal orang tua yang jauh dari sekolah. Pekerjaan orang tua responden sebagian besar wiraswasta dan karyawan swasta yang bekerja di Yayasan Imelda.

\section{Perilaku Berisiko Responden}

Tabel ini menampilkan perilaku seks pranikah yang berisiko sebelum dan sesudah mendapat edukasi. 
Tabel 2. Distribusi frekuensi perilaku sebelum mendapat edukasi

\begin{tabular}{lcc}
\hline \multicolumn{1}{c}{ Perilaku Seks Pranikah } & Jumlah & Persentase \\
\hline Berisiko & 87 & 48,3 \\
Tidak berisiko & 93 & 52,7 \\
Jumlah & 180 & 100,0 \\
\hline
\end{tabular}

Sumber : Data Primer tahun 2019

Berdasarkan tabel 2 didapat bahwa sebagian besar responden berisiko melakukan hubungan seks pranikah yaitu sebanyak 87 orang $(48,3 \%)$ dan responden yang tidak berisiko melakukan hubungan seks pranikah sebanyak 93 orang $(52,7 \%)$. Indikator perilaku seks pranikah yang berisiko adalah sikap berpacaran melakukan kissing-necking-petting-intercrause. Hasil wawancara menunjukkan sebagian responden setuju melakukan hubungan seks 1 sampai 2 kali tidak akan menyebabkan kehamilan, menurut responden kissing-necking-petting masih hal wajar selama tidak melakukan intercrause. Dapat disimpulkan bahwa perilaku berisiko seks pranikah disebabkan oleh minimnya informasi yang dimiliki oleh responden. Gejolak hormonal pada usia responden yang masih tergolong remaja dapat membuat remaja terjebak dalam hubungan seks pranikah. Hal ini sependapat dengan penelitian Admasari (2013) yang menyimpulkan bahwa ada hubungan antara pengetahuan dengan perilaku seks pranikah.

Tabel 3. Distribusi frekuensi perilaku sesudah mendapat edukasi

\begin{tabular}{lcc}
\hline \multicolumn{1}{c}{ Perilaku Seks Pranikah } & Jumlah & Persentase \\
\hline Berisiko & 42 & 23.3 \\
Tidak berisiko & 138 & 76,7 \\
Jumlah & 180 & 100,0 \\
\hline
\end{tabular}

Sumber: Data Primer tahun 2019

Hasil penelitian didapat bahwa sesudah mendapat edukasi jumlah responden yang berisiko melakukan hubungan seks pranikah yaitu sebanyak 42 orang $(23,3 \%)$ dan responden yang tidak berisiko melakukan hubungan seks pranikah sebanyak 138 orang (76,7\%). Setelah mendapat edukasi seksual pendapat dan sikap responden mengalami perubahan yang signifikan. Feriyani (2013) menyimpulkan dalam penelitiannya bahwa ada hubungan antara sikap terhadap pornografi dengan perilaku seks pranikah pada dewasa awal mahasiswa UIN Suska Riau. Perolehan informasi setelah mendapat edukasi seksual dapat merubah pandangan dan sikap responden tentang perilaku seks pranikah.

Tabel 4. Pengaruh edukasi seksual terhadap perilaku seks pranikah

\begin{tabular}{|c|c|c|c|c|c|}
\hline \multirow{2}{*}{ Perilaku Seks Pranikah } & \multicolumn{2}{|c|}{ Sebelum } & \multicolumn{2}{|c|}{ Sesudah } & \multirow{2}{*}{$P$-value } \\
\hline & $\mathbf{n}$ & $\%$ & $\mathbf{n}$ & $\%$ & \\
\hline Berisiko & 87 & 48.3 & 42 & 23,3 & \\
\hline Tidak berisiko & 93 & 52,7 & 138 & 76,3 & 0,01 \\
\hline Jumlah & 180 & 100 & 180 & 100 & \\
\hline
\end{tabular}

Sumber: Data Primer tahun 2019

Tabel 4 menunjukkan bahwa sesudah mendapat edukasi responden berisiko melakukan hubungan seks pranikah mengalami penurunan yaitu dari $87(48,3 \%)$ menjadi 42 orang $(23,3 \%)$. Setelah dilakukan uji statistik melalui uji $T$ didapat bahwa $p$ - 
value 0,01 (lebih kecil dari 0,05 ) artinya ada pengaruh edukasi seksual terhadap perilaku seks pranikah pada generasi milenial di SMK Imelda Medan. Meningkatnya libido pada masa remaja akibat kematangan fisik dan perubahan hormonal berdampak pada perilaku seksual.

Penelitian Nurhasto (2009) menyatakan bahwa penyuluhan tentang bahaya seks dapat membawa pengaruh positif terhadap perubahan perilaku seks remaja. Mahmudah (2016) dalam penelitiannya menyebutkan bahwa faktor yang paling mempengaruhi perilaku seksual remaja adalah sikap negatif dan faktor paparan tinggi dengan sumber informasi seksual. Generasi milenial sudah terpapar media internet sejak dini, hal ini mengakibatkan remaja sering mencari informasi dari internet, karena membicarakan masalah seks pada orang tua ada perasaan tabu dan malu, akhirnya mencari dari sumber lain yang dapat memberi pengaruh buruk terhadap perilaku seks. Edukasi seksual dengan cara yang tepat diharap mampu membawa pengaruh positif terhadap perubahan perilaku seks remaja. Sesudah mendapat edukasi responden berisiko melakukan hubungan seks pranikah mengalami penurunan yaitu dari 87 (48,3\%) menjadi 42 orang $(23,3 \%)$.

\section{SIMPULAN}

Setelah dilakukan uji statistik melalui uji $T$ didapat bahwa $p$-value $0,01(<0,05)$ yang berarti ada pengaruh edukasi seksual terhadap perilaku seks pranikah pada generasi millennial di SMK Imelda Medan.

\section{SARAN}

Penelitian selanjutnya disarankan menggunakan desain penelitian yang berbeda. Edukasi seksual sebaiknya menjadi bagian dari kurikulum pendidikan, sehingga dapat menurunkan resiko perilaku seks pranikah pada generasi millennial.

\section{DAFTAR PUSTAKA}

Admasari. (2013). Hubungan pengetahuan dengan perilaku seks pranikah pada remaja kelas XI di UPTD Negeri 1 Guruh Kabupaten Kediri tahun 2013.

BKKBN. (2012). Pedoman pengelolaan pusat informasi dan konseling remaja dan mahasiswa (PIK R/M). Jakarta: BKKBN.

Depkes. (2012). Modul kesehatan reproduksi remaja. Jakarta: Depkes.

Donggori, Indriana, \& Ratna. (2012). Hubungan akses media dengan pengetahuan kesehatan reproduksi pada remaja. Karya Tulis Ilmiah. Semarang: Fakultas Kedokteran UNDIP.

Feriyani. (2013). Perilaku seksual pranikah ditinjau dari intensitas cinta dan sikap terhadap pornografi pada dewasa awal. Fakultas Psikologi UIN Sultan Syarif Kasim Riau.

Hastuti, E. (2018). Perbedaan bentuk perilaku seksual remaja laki-laki dengan lawan jenis di sekolah homogen dan heterogen. Skripsi. Universitas Sanata Dharma.

Irmawati, L. (2013). Perilaku seksual pranikah pada mahasiswa. Jurnal Kesehatan Masyarakat, 9 (1).

Kusumastuti, W. (2017). Pengaruh metode psikoedukasi terhadap perilaku seksual pranikah pada remaja putri. Indigenous: Jurnal Ilmiah Psikologi, 2 (2).

Mahmudah, Yaunin, Y., \& Lestari, Y. (2016). Faktor-faktor yang berhubungan dengan perilaku seksual remaja di Kota Padang,

(http://jurnal.fk.unand.ac.id/index.php/jka/article/view/538). 
Nasria. (2010). Faktor-faktor yang mempengaruhi pengetahuan remaja tentang kesehatan reproduksi di SMA Negeri 1 Mojogedang. Tesis. Semarang: Fakultas Kesehatan Universitas Diponegoro.

Nurhasto, I. Y., Handayani, S., \& Wahyuningrum, D. (2009). Pengaruh penyuluhan tentang bahaya seks bebas terhadap sikap remaja dalam seks bebas di SMS N I Wedi Klaten. Jurnal Kesehatan.

Prasetyo. (2012). Hubungan perilaku berisiko kesehatan terhadap kecenderungan melakukan hubungan seksual pranikah di Propinsi Daerah Istimewa Yogyakarta. Tesis. Yogyakarta: Universitas Gajah Mada.

Soetjiningsih. (2009). Remaja Usia 15 - 18 tahun banyak lakukan Perilaku Seksual Pranikah, (http: // ugm.ac.id/.../551/-dr.soetjininingsih). 